\title{
Trabalho e bem-estar na polícia da Nigéria a partir dos anos 1980 foco nas divisões de polícia de Jos
}

\section{Work and welfare in the Nigeria police since the 1980s}

focus on Jos police divisions

\author{
ADOYI ONOJA \\ Departamento de História \\ Nasarawa State University \\ Keffi (Nasarawa) \\ Nigéria
}

RESUMO A polícia é uma metáfora para a crise sistêmica enfrentada pela Nigéria, especialmente desde o início da década de 1980. A crise foi anunciada pelo colapso econômico ocasionado pela má gestão e corrupção na indústria do petróleo. A intervenção do Fundo Monetário Internacional exigiu cortes em vários setores, inclusive no de segurança. Ironicamente, este foi também o período em que a necessidade de intervenção do setor de segurança foi mais urgente. Aliado ao tipo de governança - com regras militares -, a polícia foi imensamente negligenciada como a principal força para a defesa da lei e o controle da crise. As condições de trabalho e de bem estar, determinantes fundamentais da produtividade, deterioraramse junto com a expectativa crescente dos nigerianos em relação à polícia em meio à criminalidade crescente e ao colapso da ordem. Por meio de entrevistas, observações e anedotas, contadas principalmente pelos funcio-

* Artigo recebido em: 30/04/2013. Autor convidado.

**Contato: onojaa@yahoo.com. 
nários trabalhando em Jos, este artigo examina as condições de trabalho e de bem estar da polícia. Ele argumenta que a piora das condições de trabalho da polícia ocorre em função do declínio econômico, da corrupção e da preferência por um tipo de regime. Conclui-se apelando pela melhora das condições de trabalho e de bem estar como peças fundamentais para o bom desempenho da polícia.

Palavras-chave polícia, trabalho, Nigéria

ABSTRACT Police is a metaphor for the systemic crisis confronting Nigeria especially since the early 1980s. The crisis was heralded by economic collapse occasioned by mismanagement and corruption in the oil industry. The intervention of the International Monetary Fund necessitated cuts in several sectors including security. Ironically, it was also the period when the need for the intervention of the security sector was most pressing. Allied with the governance type - military rule - the police as the first line of defense in law and order crisis suffered immense neglect. Work and welfare conditions, key determinants of productivity, deteriorated as the expectation of Nigerians of the police heightened amidst growing crime and breakdown of order. Using interviews, observations and anecdotes particularly in Jos from serving personnel, the paper examines work and welfare conditions of the police. It argues that the worsening working conditions of the police is a function of economic decline, corruption and regime type preference. It concludes by calling for improve working and welfare condition as cornerstone for police performance.

Keywords police, work, Nigeria

\section{Introdução}

A visão de Souryal de que cada sociedade merece a polícia que tem é um reflexo pungente do que ocorre na Nigéria. ${ }^{1} \mathrm{~A}$ polícia está no seu ponto mais baixo de classificação em relação ao seu desempenho, em todos os tempos. O crescimento da população e a falta de crescimento proporcional na infraestrutura e nos recursos de trabalho qualificados na polícia chegam ao ponto de ruptura, enquanto as atividades desviantes proliferam. Isso ocorreu particularmente na década de 1980 quando, diante do declínio dos impostos, do aumento das despesas e da corrupção, o país foi obrigado a cortar serviços e a começar uma política de austeridade e retração.

Embora a polícia estivesse um pouco imune a essa política, como resultado do paternalismo do governo civil da Segunda República, que drenou

1 SOURYAL, Sam. Police administration and management. St. Paul, MN: West Publishing, 1977, p.7. 
recursos para a polícia como contrapeso à ameaça dos militares, o golpe de Estado de 1983, que substituiu o governo civil, mudou esse panorama. Entre suas ações iniciais, constou a retirada da atenção desproporcional dada à polícia, especialmente às condições de trabalho e de seu bem-estar, incluindo o fornecimento de modernas ferramentas de trabalho, como veículos blindados para transporte dos policiais. O golpe de 1985, que derrubou o de 1983, lançou um programa ambicioso de reformas econômicas. Ao contrário daquele sob regime civil, o efeito do programa de ajustamento estrutural abrangeria os nigerianos e as instituições. ${ }^{2}$ Certamente, apenas os militares nigerianos, por razões óbvias, foram atendidos pela administração por meio de diferentes pacotes que visavam promover seu bem-estar. A boa sorte da polícia acabou assim que a reforma econômica tomou forma.

O corte de serviços, incluindo a redução da força de trabalho no setor público, teve como efeito a proliferação de crimes de todos os tipos e o colapso da lei e da ordem. A incapacidade da polícia de controlar a situação era evidente. Ela se tornou o cartaz das consequências negativas da reforma. Os policiais eram coniventes com os criminosos, coletavam subornos, estimulavam o crime e ficavam felizes. Seus escritórios e bloqueios de estradas foram transformados em postos de pedágio para exigir taxas ilegais do público. Eles exigiam subornos e extorquiam dinheiro. Pleiteantes pagavam pela caneta e pelo papel utilizados para anotar suas reclamações; pagavam uma tarifa aos policiais para visitar a cena do crime e os policiais rapidamente transformavam o queixoso em acusado, especialmente quando a outra parte podia pagar. A decadência do sistema permeava seus edifícios. Inicialmente localizados fora da cidade, os quartéis foram construídos pelas autoridades coloniais, e não sofreram melhoria alguma na era pós-independência, exceto quando da intervenção da administração da Segunda República e do Fundo Petroleiro, que fizeram algumas obras de renovação, pois os quartéis de polícia enfeavam os centros das cidades. ${ }^{3}$

A decadência do serviço mostrava-se nesses edifícios, já que a maioria deles não estava mais apto para a habitação humana. Intervenções, como o esquema para a reabilitação dos quartéis, do extinto Petroleum Trust Fund (Fundo do Setor Petrolífero) em si, tornaram-se emaranhados de corrupção, especialmente quando ela atingiu o edifício de reabilitação da polícia. O resultado é que a maioria dos policiais está aquartelada fora dos quartéis. As intervenções improvisadas em forma de quartéis, poucas como eram, não atendiam à nenhuma das especificações mínimas. Esses foram mal

2 MKANDAWIRE, Thandika; ADEBAYO, Olukoshi. (eds.). Between liberalisation and oppression: the politics of structural adjustment in Africa. Dakar: CODESRIA, 1995.

3 Um exemplo pungente é o quartel situado à Rua Joseph Gomwalk, perto do Comando da Polícia do Estado de Plateau. Até a intervenção do governo civil do Chefe Joshua Dariye, tanto o esquema do PTF para as renovações dos quartéis quanto da renovação do Inspetor Geral de Polícia Onovo, cujas escolhas foram políticas, o lugar era um projeto de estudo, em total abandono. O lugar encontra-se parado devido às intervenções desorganizadas. 
concebidos e construídos, e eram relativamente novos quando comparados à estrutura colonial, pois estão atualmente entrando em colapso. Foi também o caso da chamada política do general Ibrahim Badamasi Babangida (IBB) (uma forma de pacote de bem-estar do governo militar mais corrupto da Nigéria, que oferecia empréstimos para aquisição de motocicletas e carros a uma taxa de juros zero aos membros dos serviços de segurança. A força policial envolvida nesse empreendimento estava mergulhada em corrupção, pois a maioria dos funcionários não se beneficiou do esquema.

Como primeira linha de defesa, a polícia está encontrando dificuldades para cumprir suas responsabilidades. O resultado é o nascimento de patruIhas policial-militares conjuntas devido à perda de confiança na polícia. Isto continua a ser o rosto da segurança interna até hoje. Este artigo examina as condições de trabalho e bem estar da polícia usando algumas divisões da polícia em Jos, capital do estado de Plateau. Metodologicamente, a escolha de Jos foi realizada devido a minha familiaridade com a área e a facilidade de realizar contatos. A metodologia de trabalho combina entrevistas, observações, anedotas e literatura secundária para situar as condições de trabalho dos policiais dentro da metrópole de Jos, sob o comando da polícia do Estado de Plateau.

Entre os desafios encontrados estão as dificuldades burocráticas, tais como a necessidade de obtenção de permissão do comissário de polícia para escrever e enviar o questionário, após minucioso exame. Outros incluem a falta de vontade dos policiais e mulheres em serem entrevistados, mesmo após a permissão ter sido concedida. A maioria deles teve medo da repercussão se fossem identificados e punidos por falarem sua opinião sobre a "podridão e corrupção" no serviço, como um deles se expressou. Eles estavam dispostos a serem entrevistados sob a condição de anonimato para evitar que fossem perseguidos e disciplinados. ${ }^{4}$ Assim, para superar o problema, eu assegurei a eles que, ao invés de usar nomes, eu usaria "fonte" ou "fontes" do "comando da polícia do Estado de Plateau", em vez das "divisões" onde eles estivessem servindo em Jos.

\section{Educação de segurança e o lugar da polícia}

Os nigerianos acreditam que a decadência e o colapso das instituições é uma das consequências do regime militar. Antes de 1999, as Forças Armadas, como instituição, tinha governado o país mais do que os governos

4 O anterior comissário de polícia do comando do Estado de Plateau, em um discurso de despedida, acusou o escalão mais alto da força de corrupção e de nepotismo na política de promoções, o que está afetando o desempenho do serviço. Por esta declaração, ele foi questionado e, de acordo com uma fonte no quartel, "seu distintivo foi retido e nenhum de nós vai querer sofrer desta maneira. Se eles podem fazer isso com um policial aposentado, o que eles podem fazer com aqueles de nós em serviço", ele perguntou. Disponível em: < http://thenationonlineng.net/ new/lawal-ogienagbon/dipo-ayeni-vs-the-police>. Acesso em: 30 abril 2013. 
eleitos. Com exceção do primeiro governo pós-independência, de 1960 a 1966, e do governo da Segunda República, de 1979 a 1983, todas as outras administrações até 1999 foram do tipo militar. De fato, a inauguração do governo eleito em 1999 foi, em si, uma forma de continuação do regime militar, enquanto os militares simplesmente entregaram o poder à sua legião de oficiais aposentados. A transição dentro da transição começou apenas em 2007, quando o falecido Presidente Yar'adua foi eleito.

Em assunto de segurança, ${ }^{5}$ a maioria dos funcionários do governo, eleitos ou designados, e os nigerianos em geral, tiveram sua educação básica sob o regime militar. Assim, sua orientação e condutas em questões de segurança são informadas por esta tradição. ${ }^{6}$ Em qual conjuntura a palavra "segurança" tornou-se ativa no vocabulário nacional? O que determinou a proeminência do termo? Responder a estas perguntas é a chave para a compreensão das condições de trabalho e bem estar da polícia e implica historicizar o desenvolvimento da Nigéria pós-independente. Segurança tornou-se uma palavra ativa quando a oferta não atendeu mais à demanda em todos os setores.

A utilização da palavra segurança no discurso foi obra do regime militar que dominou o governo da Nigéria. ${ }^{7}$ Isso aconteceu a partir da utilização incorreta da palavra nas condutas profissionais e políticas. A decadência generalizada do governo que caracterizava o regime militar tornou-se evidente após a substituição do regime autoritário por diferentes formas de governo representativo, no final da Guerra Fria. Outra consequência foi o aumento da segurança, conceitualmente e empiricamente, pelo sistema das Nações Unidas. ${ }^{8}$ Estas duas questões impactaram, coletivamente, a utilização do termo.

A primeira questão que colocou a segurança em pauta foi a Guerra Fria. Pode-se dizer que a Guerra Fria começou, em primeiro lugar, com o nascimento do primeiro estado socialista do mundo em 1917, e em segundo lugar, com o fim da Segunda Guerra Mundial. Apesar de seu antagonismo mútuo, a Segunda Guerra Mundial foi uma demonstração rara de cooperação entre dois rivais ideológicos contra um inimigo comum, o Nacional Socialismo, ou Nazismo, na Alemanha. A Guerra Fria sintetizou a desconfiança que existia entre a extinta União Soviética e os Estados Uni-

5 Na Nigéria, a segurança está centrada no Estado e, assim, essa visão realista é a popular. O exército nigeriano, o símbolo de segurança do Estado, beneficiou-se deste conceito indevido. Ver MORGENTHAU, Han. Politics among nations: the struggle for power and peace. New York: Alfred A. Knopf, 1978.

6 ONOJA, Adoyi. Putting security education in the Nigerian context. Keffi: Nasarawa State University, 2011 (História, Trabalho não publicado).

7 ONOJA, Adoyi. Regime type and the established notion of security in Nigeria: towards a human centered security for Nigerians. Trabalho apresentado no $55^{\circ}$ Congresso Anual da Historical Society of Nigeria, Tema: "Nigéria aos 50: os desafios de construção da Nação". Institute of Development Research, Ahmadu Bello University, Zaria, 25-27 out. 2010.

8 Relatório de desenvolvimento humano do PNUD, 1994. Disponível em: <http://hdr.undp.org/en/reports/global/ hdr1994/> . Acesso em: 17 abril 2012. 
dos da América; essas rivalidades abrangiam o plano econômico, político, social, intelectual, psicológico e, particularmente, o domínio militar, que se disseminaram nos estados aliados a estes dois poderes, cujas políticas eram coloridas por suas alianças.

Enquanto a Guerra Fria durou, as duas potências toleraram os excessos de seus estados satélites e, na maioria dos casos, os apoiaram generosamente, abastecendo-os econômica e militarmente. Eles toleraram até mesmo tipos de regime que violavam a maior parte do que é defendido pelo Ocidente nos dias de hoje. Esses regimes eram ou autoritários de um partido só, ou completamente militares. Com esses tipos de regimes no poder, as preocupações quanto à sobrevivência do regime dominavam a governança. Recursos econômicos eram desviados para o abastecimento das Forças Armadas e da polícia política para a manutenção do Estado.

No período da Guerra Fria, a Nigéria tornou-se um regime militar despótico. As políticas dos governos passaram a ser guiadas pela necessidade de manter a força e a estabilidade. Esses regimes não distinguiam entre sua responsabilidade profissional e política. O resultado foi que a governança ficou para trás, enquanto seus instintos profissionais passaram a controlar sua política. Os regimes militares estiveram no controle no país entre meados dos anos 1960, com uma interrupção, até o fim da Guerra Fria, em 1989. Esta situação durou até a transição de 1999.

A segunda questão que colocou a segurança na agenda do dia para os nigerianos foi o próprio tipo de regime. Notamos no exposto que, com a exceção do governo civil da Primeira República e da Segunda República, o resto do regime foi controlado pelos militares. Também observamos que, enquanto a instituição estava sobrecarregada com a guarda dos limites territoriais nacionais e, em alguns casos, acalmando perturbações que ameaçavam o Estado, os militares, ao subverterem a Constituição e assumirem a governança, não distinguiam entre os papéis profissionais e políticos. ${ }^{9}$ Os militares dominavam a política, as polícias e a sociedade. Sua dominação era tão abrangente que incluía as estruturas do governo, o que unificava sua disposição de comando e o significado, a compreensão e a aplicação das ideias, como segurança e defesa. O curto período de regime civil pouco fez para livrar os nigerianos desta forma de socialização que estava difundida. Com o retorno dos militares aposentados como membros do executivo e do legislativo de 1999 a 2007, a oportunidade de começar um processo de desmilitarização da política pareceu perdida. A ruptura com o passado pareceu infiltrar-se lentamente com a chegada ao poder do falecido presidente Umaru Musa Yar'Adua e a resolução da quase insolúvel crise do Delta do Niger. Como a classe política foi criada pelos

9 ONOJA, Adoyi. Regime type and the established notion of security in Nigeria. 
militares, na maioria das áreas, em relação aos inúmeros programas de transição que eles organizaram, ela também foi afetada pela mentalidade militar, particularmente em sua percepção do que ameaça a sua posição.

Isso é demonstrado pelo fato de que, da geração que nasceu a partir de meados dos anos 1960 até o fim da década de 1980, o sistema de governo mais familiar para eles é o militar. ${ }^{10}$ Os militares funcionam, muitas vezes, como sociedades dentro da sociedade, tendo suas próprias comunidades militares, economia, educação, medicina, língua ${ }^{11}$ e outros aspectos de uma sociedade civil em funcionamento. A socialização é o processo pelo qual os indivíduos aprendem a cultura de sua sociedade. ${ }^{12}$ Para além das famílias, grupos de pares, escolas, ambientes de trabalho, a instituição militar foi uma das agências não oficiais de socialização na Nigéria. A forma de socialização dos militares ficou consolidada na sociedade em geral, enquanto a Nigéria foi transformada em uma grande guarnição.

A terceira questão que colocou a segurança em pauta foi o ambiente pós Guerra Fria e pós 9/11. O mundo pós Guerra Fria se refere ao ambiente surgido com o fim da Guerra Fria. O desaparecimento da União Soviética retirou a base da rivalidade, deixando os Estados Unidos como a única superpotência. Sob esta condição, a busca da liberdade econômica e de democratização tornou-se a única preocupação dos Estados Unidos. O ambiente pós 9/11 seguiu-se à destruição das Torres Gêmeas e o ataque ao Pentágono pela Al-Qaeda, sinalizando o nascimento de um grupo não estatal, com a capacidade de ameaçar a segurança do Estado. ${ }^{13} \mathrm{O}$ ataque desafiou o modelo predominante de relação e criou uma nova ameaça que os Estados Unidos passaram a conter. Lançou a guerra contra o terror, que incluiu a invasão do Iraque em bases não justificáveis e a remoção do Taliban do Afeganistão. A renovada preocupação com a segurança tornou-se a prioridade do governo dos Estados Unidos. Esta prioridade foi exportada para outros governos em todo o mundo. Hoje, a Nigéria é confrontada com o que a autoridade denominou como insurgências, em diferentes partes do país.

O período da Guerra Fria foi caracterizado pela restrição em nome da estabilidade e, acima de tudo, pelo não reconhecimento do clamor pela reparação das condições desumanas, por medo que ele poderia prejudicar tanto os Estados Unidos, quanto a União Soviética e seus aliados. Assim, nesta época, a maioria das formas de agitação foi contida sem levar em conta qualquer protocolo nacional ou internacional. O relaxamento das

10 Isto foi validado pela pesquisa realizada entre os alunos da Nasarawa State University, 2010

11 OJO, Oluwaseyi. Military language and democratisation in Nigeria. In: OLOWU, Dele; WILLIAMS, Adebayo; SOREMEKUN, Kayode (org.). Governance and democratisation in West Africa. Dakar: CODESRIA, 1999.

12 HARALAMBOS, Michael. Sociology: themes and perspectives. Slough: Tutorial University Press, 1983, p.4-5.

13 KRAHMANN, Elke. Conceptualizing security governance. Cooperation and Conflict, v.38, n.1, p.5-26, 2003; KRAHMANN, Elk. Security governance and networks: new theoretical perspectives in transatlantic security. Cambridge Review of International Affairs, v.18, n.1, p.19-34, 2005. 
restrições que o fim da Guerra Fria representou desencadeou agitações que estiveram silenciadas no auge da Guerra Fria. Houve clamor por uma mudança de regime, pelo respeito aos direitos humanos, aos direitos das minorias, da democratização e, acima de tudo, dos protocolos internacionais e os governos do Ocidente tornaram-se receptivos a estes clamores.

Na Nigéria, os militares ficaram sob intenso escrutínio de grupos locais não-governamentais de direitos humanos sobre sua forma de conduzir os assuntos econômicos e políticos. Esse escrutínio contou com o apoio das organizações internacionais e dos governos. Foi essa atmosfera que colocou no centro da política as questões da marginalização e da degradação ambiental no Delta do Níger, da anulação da eleição presidencial de 1993, do conflito no centro da Nigéria, especialmente no Planalto, e da chamada dos militares de volta aos quartéis. A proliferação de grupos armados e não armados na área foi descrita pelo regime militar como ameaça à segurança nacional e, com base neste argumento, o regime mobilizou soldados para sufocar a rebelião.

A quarta questão foi que o ambiente pós-Guerra Fria expôs a tradição de governança ruim, que é predominante na Nigéria. A governança, no período do regime militar, foi caracterizada pela falta de planejamento, pela corrupção e pela falta de infraestrutura. A centralização da maioria das instituições criou condições que restringiram o crescimento de demandas locais em um país heterogêneo como a Nigéria. Foram os militares que abandonaram o plano de desenvolvimento nacional, o que abriu espaço para planos de desenvolvimento a curto, médio e longo prazo em detrimento dos planos ad hoc. Na maioria das áreas de desenvolvimento, a demanda suplantou a oferta, criando a oportunidade para desencadear tendências de conflito, tais como nepotismo, disputas étnicas e religiosas, na maioria das instituições da sociedade. As oportunidades desperdiçadas pelos militares, tais como o boom do petróleo, nas décadas de 1970 e 1990, criaram a base da chamada insegurança, que se tornou sua preocupação. Com uma economia que não se expandiu para atender às necessidades crescentes de postos de trabalho, com escolas, hospitais, áreas de recreação inadequadas e subfinanciadas e com a corrupção desfrutando de um lugar de destaque em classificações internacionais, ${ }^{14}$ o país estava pronto para colher agitações em consonância com o ambiente que as criou. O declínio na qualidade de vida dos nigerianos foi descrito como insegurança pelo regime militar e pela classe política que o criou. A solução clássica foi colocar os soldados na rua para conter a situação.

A quinta questão, decorrente da terceira e da quarta, foi o foco no bem estar humano, desencadeado pelas organizações internacionais, especial-

14 Índice de Percepção da Corrupção, 2011. Disponível em: <www.cpi.transparency.org/cpi2011/result/>. Acesso em: 30 abril 2013. 
mente o sistema das Nações Unidas. Em 1994, o Programa das Nações Unidas para o Desenvolvimento (PNUD) publicou um documento que introduziu o conceito de Segurança Humana. ${ }^{15}$ Segurança Humana significa "em primeiro lugar, proteção contra ameaças crônicas, tais como fome, doenças e repressão. E, em segundo lugar, significa proteção contra interrupções repentinas e prejudiciais nos padrões de vida - tanto diariamente nos lares, quanto no trabalho ou nas comunidades." Garantir a segurança humana requer uma abordagem em sete frentes diferentes para garantir a segurança econômica, alimentar, ambiental, da saúde, dos funcionários, comunitária e política. ${ }^{16}$ Assim, os períodos de regime militar testemunharam o aumento das despesas nas capacidades ofensivas e defensivas enquanto, correspondentemente, declinaram a alocação de recursos na saúde, no saneamento, na infraestrutura, na escola e na criação de empregos. ${ }^{17}$ Gastos militares significam falta de oportunidade para resgatar os serviços sociais em declínio e infraestruturas em desintegração.

Os custos humanos decorrentes das despesas militares não são apenas altos, mas também produzem a insegurança com a qual o regime é obrigado a justificar suas medidas. ${ }^{18}$ As despesas militares na Nigéria não podem ser justificadas pela necessidade de segurança contra ameaça externa; ao invés disso, a falta de atenção ao bem-estar das pessoas está criando as condições para os conflitos internos. ${ }^{19} \mathrm{O}$ nível de pobreza na Nigéria é tal que a luta pela existência social é travada em um nível de proximidade física tão absorvente e debilitante que é hostil à condição de segurança. Esta é a definição de segurança que os militares legaram aos nigerianos no contexto do nascimento de uma civilização da política. $\mathrm{Na}$ ausência de condições materiais para a democratização, prevalece essa noção de segurança. Portanto, a segurança tornou-se a preocupação de todos, desde o leigo até o profissional.

A polícia ficou para trás nesse contexto de segurança. Já não era a primeira linha de defesa na segurança interna. O ambiente operacional foi sustentado pela violência que o treinamento e os recursos da polícia eram incapazes de controlar. A polícia tem demonstrado sua inadequação na manutenção da ordem, que as instituições funcionais, começando pela família e pela escola, deveriam ter melhorado. Os militares, como gerentes da violência, tornaram-se a cara da lei e da ordem.

15 HAMPSON, Fen Osler. Human security. In: WILLIAMS, Paul D. (org.). Security studies: an introduction. London: Routledge, 2008, p.229-243; ver também BOOTH, Ken. Theory of World security. Cambridge: Cambridge University Press, 2007, p.68-69.

16 KERR, Pauline. Human security. In: COLLINS, Alan. (org.). Contemporary security studies. Oxford: Oxford University Press, 2010, p.122.

17 AKE, Claude. The feasibility of democracy in Africa. Dakar: CODESRIA, 2005, p.145.

18 OLUWASEGUN, Victor; ANOFI, Dele. Military, police allocated 20\%. The Daily Nation. Friday, November 9. v.2, n.0467, p.2, 2008.

19 Desde o retorno do governo civil, o conflito tem se proliferado no país. 


\section{A má gestão econômica e a polícia}

A crise da Nigéria é orientada pela governança. ${ }^{20} \mathrm{O}$ aumento do abismo entre a promessa e o desempenho dos políticos, sejam militares ou civis, tem continuamente criado desconfiança, resultando em frequente instabilidade na política. Com a independência, os nigerianos herdaram uma sociedade polarizada ao longo de linhas étnicas, religiosas e regionais, com vários graus de esclarecimento e ignorância. Apesar da situação, os nigerianos foram unânimes no seu desejo coletivo de viver uma vida melhor, tal como consta nas promessas feitas a eles pelos líderes da independência. A economia, portanto, oferece a explicação principal para as diferentes crises que atormentam o país, como a intolerância étnica e religiosa, as disputas de terra e de chefia, a instabilidade política e as crises sociais, tais como a prostituição e o assalto à mão armada. ${ }^{21} \mathrm{~A}$ divisão entre os grupos favorecidos e desfavorecidos continham as tendências para que as forças centrífugas e centrípetas agissem. O estopim se deu com a independência, na qual o edifício colonial tinha edificado seus alicerces. ${ }^{22}$

A agricultura era o baluarte da economia da Nigéria no momento da independência. As regiões se envolveram em uma competição relativamente saudável na divisão do trabalho e na produção de diversos produtos agrícolas. O norte produzia amendoim, couro, pele e algodão; o leste produzia óleo de palma e o oeste cacau e borracha. Qualquer evidência de extrações minerais nas regiões não eclipsou a importância da agricultura. Até aquele momento, petróleo e gás não tinham destaque nas atividades econômicas. A competição pela alma do Estado era menos rígida, especialmente no que dizia respeito ao centro. No entanto, houve problemas, com importantes desdobramentos econômicos e políticos, que colocaram as regiões umas contra as outras. Isso incluiu os censos, a fórmula de alocação da receita, as eleições e a busca da vantagem eleitoral e do apoio das minorias no interior de cada região, contra o desejo de exclusividade dos blocos no poder. No final do primeiro quarto da década de 1960, era evidente que a intolerância crescente entre os políticos tinha atingido seu auge. ${ }^{23}$

Em 1964, a coalizão que controlava o governo federal tinha, no que se tornaria a fase de segurança conflituosa, enviado tropas para a Divisão Tiv, da Província Benue. ${ }^{24} \mathrm{O}$ fraco regime político, nesta fase, era particularmente vulnerável à implosão de crises em pequena escala. O Estado se tornou

20 LEFTWICH, Adrian. Democracy and development in the Third World. Third World Quarterly, v.14, n.3, p.605-624, 1993; WORLD BANK. Sub Saharan Africa: from crisis to sustainable growth. Washington, DC: The World Bank, 1989; WORLD BANK. Governance and development. Washington, DC: World Bank, 1992.

21 AKE, Claude. A political economy of Africa. Inglaterra: Longman, 1981, p.1-30

22 AKE, Claude. Democracy and development in Africa. Ibadan: Spectrum, 1996, p.1-3

23 CROWDER, Michael. The story of Nigeria. Londres: Faber and Faber, 1961.

24 VIKING, Steffan. Military coups in Sub-Saharan Africa: how to justify illegal assumptions of power. Suécia: SIAS, 1983, p.53-57. 
esquelético, em parte porque estava assolado por clivagens políticas verticais entre os grupos étnicos com bases regionais, ao invés de clivagens horizontais, baseadas nas classes sociais..$^{25} \mathrm{O}$ desenvolvimento era um indicativo do mal funcionamento das instituições em níveis federal e regional, enquanto o espectro do mal estar separatista havia infectado a maioria das instituições nacionais, exceto a militar. Ou foi o que eles disseram. ${ }^{26}$

Crises semelhantes, como as que a Nigéria teve que confrontar, também se tornaram evidentes na maioria dos países da África subsaariana. A consequência foi o crescente isolamento da elite política de seus pares, já que ela estava em guerra com o resto da sociedade e com facções rivais no interior de suas próprias fileiras, e as pessoas acharam que a violência era inevitável. Dessa maneira, a competição política passou a assumir o caráter de uma guerra e abriu caminho para a ascensão dos especialistas em violência, os militares. A onda de golpes militares que veio mais tarde, essencialmente, formalizou uma realidade que já estava, então, firmemente estabelecida. Não foram os militares os causadores do regime militar na África por meio da sua intervenção na política. Pelo contrário, foi o caráter da política ao se degenerar em guerra, que gerou o regime militar e, inevitavelmente, conferiu o papel principal aos especialistas em guerra. ${ }^{27}$

O golpe de estado no Egito, em 1952, teve uma implicação a longo prazo para os países da África subsaariana. Quando a competição pelo poder e por recursos erodiu qualquer legitimidade que os líderes da independência possuíam e os líderes dos golpes surgiram para substituí-los, as justificativas foram quase as mesmas em todos esses países. Elas incluíam críticas aos políticos por suas intrigas e sua luta pelo poder, a falta de legitimidade, o declínio do padrão de vida, o auto-enriquecimento e a corrupção, os distúrbios no país, os políticos que representavam uma ameaça à segurança pública, a deterioração da segurança pública, evitando derramamento de sangue, protegendo as instituições democráticas, a economia mal administrada e o aumento do custo de vida. ${ }^{28}$ As explicações oferecidas a favor da intervenção militar na política, além daquelas dadas pelos golpistas, incluíram aquelas ligadas aos interesses e às influências estrangeiras, às condições sociais, às relações governamentais e militares, às condições intra-militares e às perspectivas individuais. ${ }^{29}$

Após o boom do petróleo, na década de 1970, a Nigéria negligenciou sua capacidade de produção agrícola e sua fraca produção manufatureira, em favor da dependência insalubre em relação ao petróleo bruto. Em 2002,

25 DOGAN, Mattei; HIGLEY, John. Elites, crises, and the origins of regimes. Lanham, Maryland: Rowman and Littlefield, 1998, p.11.

26 VIKING, Steffan. Military coups in Sub-Saharan Africa, p.79-99.

27 AKE, Claude. Democracy and development in Africa, p.6.

28 AKE, Claude. Democracy and development in Africa.

29 AKE, Claude. Democracy and development in Africa, p. 23-69. 
as exportações de petróleo e gás representavam mais de $98 \%$ das receitas de exportação e cerca de $83 \%$ das receitas do governo federal. ${ }^{30} \mathrm{~A}$ nova riqueza oriunda do petróleo, o concomitante declínio de outros setores da economia e a adoção de um modelo econômico impulsionaram a migração maciça para as cidades e levaram a uma pobreza cada vez mais difundida, especialmente nas áreas rurais. O colapso da infraestrutura básica e dos serviços sociais, desde o início da década de 1980, ocorreu paralelo a este desenvolvimento. A agricultura tem sofrido com anos de má gestão, políticas governamentais inconsistentes e mal concebidas e com a falta de infraestrutura básica. No entanto, o setor responde por cerca de $30 \%$ do PIB e dois terços dos empregos. A agricultura sustentou uma significativa parcela do crescimento não-petrolífero, que, em 2006, chegou a 9\%. O campo contém potencial para o crescimento. No entanto, o sistema de posse de terras da Nigéria não incentiva o investimento a longo prazo em tecnologia ou em métodos modernos de produção e nem estimula a disponibilidade de crédito rural. ${ }^{31}$

A dependência do petróleo criou a impressão de que ele gera grande riqueza por meio de contratos governamentais e gerou outras distorções econômicas. A alta propensão para a importação significa que cerca de $80 \%$ das despesas do governo foram gastas no comércio com o estrangeiro. Importações de consumo baratas - resultantes de uma naira* supostamente supervalorizada e de elevados custos de produção doméstica resultantes, em grande medida, de um fornecimento errático de eletricidade e combustível - levaram à redução da utilização da capacidade industrial para menos de $30 \%{ }^{32}$ e resultaram no fechamento completo de muitas indústrias. $O$ colapso da infraestrutura de transporte público é um dos principais entraves para o desenvolvimento econômico. O que é fascinante sobre a geração de receita é a dependência quase exclusiva de receitas do governo nos três níveis para serem alocadas de acordo com os estatutos, a última delas dependente das rendas provenientes do petróleo. ${ }^{33}$

A intervenção tornou-se uma característica permanente da vida política quando esta começou, em 1966. Entre 1966 e 1999, o governo civil esteve apenas quatro anos no comando, de 1979 a $1983 .{ }^{34} \mathrm{O}$ ambiente internacional da Guerra Fria tornou possível a perpetuação do regime militar. Os Estados Unidos foram favoráveis a qualquer tipo de regime que não fosse comunista. Isso não é muito diferente do apoio que ele oferece a outros regimes

30 CENTRAL BANK OF NIGERIA. Statistical Bulletin, Abuja, v.16, 12/2005.

31 UMARU, Ibrahim. The current global financial meltdown and implications for the Nigerian economy. Keffi: Department of Economics, Nasarawa State University, 2009 (Texto não publicado).

* [NT] Naira - Moeda em curso na Nigéria.

32 UMARU, Ibrahim. The current global financial meltdown and implications for the Nigerian economy, p. 12.

33 UMARU, Ibrahim. The current global financial meltdown and implications for the Nigerian economy, p.13.

34 OYEDIRAN, Oyeleye; AGBAJE, Adigun. Nigeria: politics of transition and governance, 1986-1996. Dakar: CODESRIA, 1999, p.12. 
enquanto a guerra contra o terror se desdobra. Foi a rivalidade entre oficiais militares, que representavam diferentes clivagens étnicas e políticas, que culminou na guerra civil. ${ }^{35} \mathrm{O}$ governo militar continuou com graus variados de interrupção: houve uma breve tentativa de um governo civil, de 1979 a 1983, e a transição prolongada do general Ibrahim Babangida que, apesar de não resultar em um governo civil, criou a base para o retorno dos oficiais militares aposentados na política do país, em $1999 .{ }^{36}$ Consequentemente, a base de sustentação da democracia esteve ausente quando se considera os níveis político, sociocultural e econômico. ${ }^{37}$

O efeito da reforma econômica na polícia tornou-se visível. Como representantes da segurança pública e da ordem, eles se tornaram o para choque entre o povo e o governo. O controle das greves, das manifestações e da insegurança em relação à vida e aos bens são de responsabilidade da polícia. Como ela estava mal equipada e motivada, era incapaz de executar bem o seu dever. O declínio da confiança dos nigerianos na polícia e o reconhecimento da autoridade majoritariamente militar resultaram na disposição dos soldados de ajudarem a polícia com o objetivo de manter a segurança interna. O efeito da reforma econômica nos membros das Forças Armadas foi amenizado com diversos pacotes de bem-estar, fornecidos pelos governos. ${ }^{38}$

A polícia não era uma prioridade neste esquema de bem estar e a parcela de recursos destinada a eles foi pelo ralo da corrupção. Por isso, o público suportou e ainda suporta o peso de manter homens e mulheres policiais mal pagos, financiados pela extorsão e pelo suborno. Em um artigo denunciando a corrupção na polícia, Odinkalu opinou que

o problema não é simplesmente de fraude e suborno (...) a polícia é, na melhor das hipóteses, mal equipada. Um em cada quatro policiais existe apenas no papel: os chefes recolhem o pagamento extra. ${ }^{39}$

A corrupção, especialmente no topo, está afetando o desempenho da força e os dissidentes de dentro e de fora dos seus quadros estão sendo punidos por denunciarem-na. ${ }^{40}$

35 ADEJO, Armstrong Matiu. The Nigerian Civil War forty years after: what lessons? Makurdi: Aboki, 2008.

36 ONOJA, Adoyi. The ex-military class in Nigeria's democracy: implications for the legislature. Trabalho apresentado no Governance Institute, Dakar: CODESRIA, 2007; OYEDIRAN, Oyeleye; AGBAJE, Adigun. Nigeria, p.14-15.

37 OYEDIRAN, Oyeleye; AGBAJE, Adigun. Nigeria, p.5-10.

38 Uma vez que o regime era liderado principalmente por militares, isso era uma necessidade existencial com o objetivo de amortecer o efeito da economia em declínio no bem estar das Forças Armadas, evitando assim a desestabilização do governo. A polícia não ameaçava o suficiente para ser incluída no esquema.

39 ODINKALU, Chidi Anselm. Mr. President, its time to halt impunity. ThisDay Lawyer. Tuesday, May 31, 2011, p.x.

40 O superintendente Alozie Ogugbuaja foi retirado do serviço em 1986, por falar contra a corrupção no âmbito da administração militar e seu impacto na sociedade. Recentemente, o comissário de polícia aposentado, e comandante do Estado de Plateau, o Sr. Emmanuel D. Ayeni foi questionado e está sendo investigado pela Comissão do Serviços da Polícia por acusar o alto escalão de corrupção e de minar o profissionalismo e o mérito. Disponível em: <http://www.punchng.com/news/police-reforms-cosmetic-outgoing-cp/> e < http://thenationonlineng.net/ new/lawal-ogienagbon/dipo-ayeni-vs-the-police/> . Acesso em: 22 mar. 2013 


\section{Trabalho e bem estar nas Divisões de Polícia em Jos}

O comando da polícia do estado de Plateau é composto por divisões policiais sediadas em cada um dos dezessete conselhos locais que compõem o governo do estado. Cada conselho de governo local tem uma divisão. Jos, a capital do estado, tem cerca de sete, incluindo as divisões A, B, C, e Laranto. Cada divisão é subdividida em estações e postos. As estações são maiores e comandadas por oficiais superiores da polícia, enquanto os postos são menores, com oficiais superiores não comissionados no seu comando. ${ }^{41}$ As divisões onde eu realizei o trabalho de campo - A, B, C e Laranto - são formadas por esta estrutura. Estão alocadas nestas divisões entre 182 a mais de 200 pessoas. As estações têm cerca de 10 funcionários e os postos têm menos. ${ }^{42}$

Para a maioria dos policiais nigerianos, a polícia não era a sua primeira opção entre as carreiras disponíveis. ${ }^{43}$ Isso é recorrente, particularmente, a partir da década de 1980. A maioria das pessoas que se juntou à força neste período fez isso para permanecer empregada. Entre outros motivos citados para isso, dependendo do quadro, não estavam incluídos o serviço ao povo. ${ }^{44} \mathrm{O}$ declínio das oportunidades na década de 1980 e a contração da economia derivada da adoção do programa de ajustamento estrutural obrigaram alguns nigerianos a se juntarem à força policial. O centro de treinamento e o currículo permaneceram inalterados. Os homens e as mulheres treinados e equipados nestas instalações, sem nenhuma motivação além de servir, são os que foram colocados nas ruas para policiar os nigerianos.

O ambiente de trabalho não é melhor do que aquele obtido em suas escolas de formação. Os soldados eram alocados nos quartéis, divisões e estações estatais, espalhados por todo o país. Como será demonstrado nas divisões policiais metropolitanas em Jos, esses homens e mulheres trabalharam sob condições extremas, muitas vezes sem nenhum material de trabalho, como mesas, cadeiras, computadores, armários para arquivos, documentos e canetas. Os quartéis divisionais estão em um estado de abandono, onde janelas estão caídas, sem persianas, escritórios abarrotados, instalações sanitárias inadequadas, abastecimento de água e de eletricidade erráticos, sem substitutos adequados. Um edifício de sede divisional protótipo existe dentro das divisões policiais em todo o país. No comando do estado de Plateau, o edifício, especialmente o das divisões B,

41 Trabalho de campo, 13 e 14/03/13.

42 Entrevistas, fontes nas divisões C e B, 21/03/13 e 22/03/13.

43 Em um bate-papo com uma das minhas fontes na divisão, ele parece expressar pesar em integrar a polícia pois questões como promoção são previsíveis em outras profissões, como na universidade:"Meus companheiros que escolheram ensinar são professores agora. Eu tenho um mestrado. Minha última promoção foi em 2006 e eu não sei quando virá a próxima".

44 ONOJA, Adoyi. Sustaining a tradition of policing through alienation: an assessment of recruitment and training in the colonial and postcolonial Nigeria police. Afrika Zamani, n.13/14, p.123-137, 2005/2006. 
C e Laranto, foi construído no formato da letra "T". A entrada está situada no meio da borda do "T", onde está localizado o balcão para reclamações e informações. ${ }^{45}$ Após passar por este balcão, há um corredor à esquerda e outro à direita, onde estão situados os escritórios, incluindo o do Comandante Divisional de Polícia (CDP), o do Comandante Divisional de Crime (CDC), o da Administração Policial, o de Interrogatório, entre outros e a cela de detenção de suspeitos.

Na Divisão $\mathrm{C}$, há dois blocos que a minha fonte descreveu como os edifícios antigo e moderno. O antigo edifício colonial foi herdado da antiga Autoridade Nativa de Jos, enquanto o novo é em forma de "T". O antigo edifício parecia melhor e construído de maneira mais adequada, quando comparado ao decadente novo prédio. Este edifício colonial abrigou o CDP e alguns de seus homens. O novo edifício abriga outros funcionários, incluindo as celas de detenção de suspeitos. Minha fonte descreveu a condição dos equipamentos como precisando desesperadamente de substituição. Mostrando-me as cadeiras e as mesas no escritório do chefe da estação, a minha fonte queixou-se de que ele as encontrou assim quando foi transferido para a Divisão, em 2009:

Os funcionários da polícia têm que comprar suas próprias canetas e papéis; não há armários aqui e pode-se ver os documentos se acumulando e competindo pelo espaço com os funcionários; não há eletricidade, não há espaço de lazer para os homens em espera, eles ficam sob as árvores, em qualquer barraca ou espaço que conseguirem encontrar; há quatro banheiros no edifício, um dos quais é do CDP, um para oficiais superiores da polícia, um para as 14 mulheres na Divisão e o restante para os homens - no total existem cerca de 200 homens na Divisão; a eletricidade e a água não são constantes, temos um veículo de patrulha - uma caminhonete Peugeot - que está precisando de substituição; com três estações espalhadas em toda a área comercial de Jos, um veículo de patrulha epiléptico não é o suficiente. ${ }^{46}$

Um dos CDPs observou, em um bate-papo comigo, que noventa por cento do trabalho policial de hoje é de patrulha. No entanto, "a nossa polícia não pode patrulhar porque não existem veículos de patrulha". ${ }^{47} \mathrm{Em}$ uma Divisão com 13 estações e postos não há nenhum veículo de patrulha funcional para facilitar a detenção, que é a principal função da patrulha, assim como responder aos pedidos de socorro em toda a Divisão C, em estações e em postos distantes. De acordo com o Comandante:

Quando fui enviado para a Divisão, em 2009, não havia nenhum veículo de patrulha funcional. A pick-up da Divisão estava estragada. Recebi dezenas de

45 Observação de campo do prédio da polícia nas divisões B, C e Laranto, 02/03/13, 06/03/13 e 09/03/13.

46 Entrevista, Fonte: Comando de Polícia do Estado de Plateau, 22/03/13.

47 Entrevista, Comando de Polícia de Plateau, 23/03/13. 
chamados de socorro, além de estar em permanente estado de alerta devido à crise perene, que tem marcado a existência no Estado já há algum tempo. Usei meus recursos pessoais para colocar o veículo de patrulha de volta na estrada. Mas isso é insuficiente. Precisamos de mais caminhões e vans de patrulha. Quando eu servia em delegacias nos Estados Unidos, uma delegacia do tamanho desta divisão poderia ter mais de uma centena de carros de patrulha espalhados por diferentes partes do distrito, encurtando o tempo de resposta a pedidos de socorro e contendo, portanto, o crime. Aqui, muitas vezes, eu usei o meu carro pessoal para esta finalidade. ${ }^{48}$

Esta observação anterior foi corroborada por outros CDPs nas divisões em Jos. Na Divisão A, por exemplo, há 826 funcionários. Deste número, apenas 280 funcionários estão em campo. Deste número, cerca de 60 funcionários estão em missões diferentes, incluindo pacificações, tarefas especiais e esportes. Dos nove ou menos postos existentes, dois tiveram que ser fechados devido à "falta de funcionários" ${ }^{49}$ Na presente força, a divisão está realizando dificilmente o policiamento da área. Com a escassez de mão de obra, você pensaria que a disponibilidade de veículos de patrulha compensaria essa deficiência. Há dois veículos de patrulha na Divisão e apenas um é utilizável. O veículo de patrulha inadequado obrigou o uso de patrulha a pé para complementar. Segundo a minha fonte:

Esta divisão é o carro-chefe das divisões na capital do estado, uma vez que grande parte do governo e das instalações privadas, como a Casa do Governo, a Assembleia da República, os tribunais, os bancos, as sedes da igreja, as Áreas de Reserva do governo, estão localizados sob sua jurisdição. Com apenas um veículo funcionando, há pouco que podemos realizar em termos de policiamento adequado da área. Isso vale para explicar a situação de outras divisões não tão afortunadas como esta. ${ }^{50}$

Este status de "carro-chefe" é demonstrável pela diferença na sua construção. Ao contrário do prédio em forma de "T" da polícia, comum em outras divisões, a divisão A tem uma estrutura de um andar, o que constitui a única diferença em relação às demais. Em termos de qualidade, o prédio é estruturalmente tão defeituoso quanto as outras estruturas em forma de "T", já que foram, em primeiro lugar, mal construídas. Ele tem muitos escritórios escassamente mobiliados em comparação com as outras estruturas; com mais de 10 instalações sanitárias, um refeitório e celas para os suspeitos. Sobre a mobília, minha observação e interação revelaram que a única vez que tiveram móveis novos foi quando construíram o edifício. De acordo com uma fonte, o mesmo foi recentemente repintado, mas "nada foi feito para

48 Entrevista, Comando de Polícia de Plateau, 23/03/13.

49 Entrevista, Comando de Polícia de Plateau, 28/03/13.

50 Entrevista, Comando de Polícia de Plateau, 28/03/13. 
mudar as mesas e cadeiras". Há computadores, scanners, fotocopiadoras e armários para a divisão. No entanto, estes são insuficientes e sobrecarregados. A crônica inconsistência no abastecimento nacional de energia elétrica e de água afeta a divisão. Na verdade, para amenizar o problema da água, o CDP que assumiu o cargo há nove meses atrás construiu um novo poço artesiano. ${ }^{51}$ Há um gerador de reserva, que é usado ocasionalmente quando não há eletricidade e, como se trabalha à noite, está constantemente ligado durante este período. ${ }^{52}$

A constante falta de equipamentos de trabalho nestas divisões também serve para outras divisões espalhadas por todo o Estado, mesmo estando a maioria delas assentadas sobre um barril de pólvora prestes a explodir a qualquer momento. O Estado de Plateau sofreu crises incessantes desde a década de 1990 que, em vez de decrescerem, estão em ascensão. O governo nigeriano está comprometendo recursos enormes com a segurança, além da alocação orçamental regulamentar para as agências de linha e os departamentos responsáveis por diferentes aspectos da lei e da ordem. Existe a crença, em alguns quartéis, que a crise em diferentes partes do país é orquestrada por certos grupos poderosos que controlam aspectos diferentes do fracassado e instável estado nigeriano para seu próprio benefício. A classe política e a corrupção, presentes no estabelecimento de segurança e de defesa da Nigéria, são vistas como responsáveis por esta crise.

O exército nigeriano, em particular, é visto como responsável pela escalada da crise, mais por causa das vantagens financeiras obtidas, especialmente, pelo escalão mais alto da liderança. Há uma Força Tarefa Unida, ou FTU, que é uma força combinada de patrulha e intervenção no local, que trabalha "o tempo todo" para garantir a paz nas áreas propensas a conflitos na Nigéria. A FTU foi acusada pela população e pelas autoridades dos governos estaduais e municipais dentro da força de atos que perpetuam o conflito. ${ }^{53}$ Como resultado da acusação incessante de cumplicidade da FTU no Estado de Plateau, a autoridade federal permitiu a criação de uma Força-Tarefa Estadual, ou FTE, para complementar ou mesmo aniquilar as atividades da FTU. ${ }^{54}$ Centenas de veículos de patrulha e equipamentos de

51 Trabalho de campo em 26/03/13, realmente havia um poço recém-escavado no quintal da divisão.

52 Entrevista, Comando de Polícia de Plateau, 28/03/13.

53 Há unanimidade sobre isto no Estado de Plateau.

54 Entrevista, Professor Sati Umaru Fwatshak, Departamento de História e Estudos Internacionais da Universidade de Jos, 13/03/13; Interação com o Coordenador da Operação Arco-Íris, aposentado Air Vice Marshal Danbaba Bala nas reuniões em grupos de Pessoas Eminentes e Peritos sobre insurgências complexas na Nigéria, Instituto Nacional de Política e Estudos Estratégicos, Kuru, 28 de agosto de 2012; resposta de e-mail na sexta-feira, 21 de setembro, 2012 6:15 do Air Vice Marshal Danbaba Bala, o qual aludiu a "certos grupos que querem controlar segurança e sistema de defesa da Nigéria, os militares assumindo funções policiais por causa do dinheiro envolvido, esses grupos tem a sua própria força de intervenção controlada pelo Estado e não querem que o Plateau e os outros estados tenham a deles. Estas são questões para refletir há uma convicção em todo Estado de Plateau que a crise vigente está sendo orquestrada por muitos interesses consolidados". Ver ONOJA, Adoyi. What is wrong with solutions to insecurity in Nigeria? Disponível em: <http://sundaytrust.com.ng/index.php/comment-debate/5977what-is-wrong-with-solutions-to-insecurity-in-nigeria>. Acesso em: 24 mar. 2013. 
comunicação são regularmente comprados para o trabalho da FTU em áreas de crise em toda a Nigéria. À polícia, que é a primeira linha de defesa para a eclosão do conflito, são negadas essas facilidades constantemente.

Em uma das Divisões que visitei em Jos, um policial do posto elogiou seu CDP pela utilização de alguns de seus fundos pessoais para colocar o veículo da Divisão de volta ao serviço. Em outro, o CDP confirmou que seu escritório foi renovado com seu próprio fundo porque, "quando eu assumi o dever, o escritório não era nem um pouco apropriado". Em uma entrevista com o oficial da administração, ele confirmou que, quando o Inspetor Geral Onovo estava no comando, em 2010, reformas ocasionais foram realizadas em divisões policiais e sua divisão estava "incendiada, como você pode ver", mas "o trabalho parou antes mesmo que ele fosse removido como chefe da polícia e o empreiteiro nunca mais voltou ao local". ${ }^{55}$ Ele reclamou que existem três instalações sanitárias para os homens e mulheres da Divisão, o que não é adequado, e não há espaço para recreação ou cantina.

Sobre a suficiência dos salários, a maioria dos policiais que eu entrevistei e com quem interagi queixou-se do efeito da inflação sobre seu pagamento e pedia por uma revisão. Alguns entrevistados gostariam que o governo contivesse a tendência inflacionária da economia. Um deles argumentou que tal valor da inflação, procedente do Banco Central da Nigéria, é manipulado pois não reflete o que "os nigerianos vivem quando vão ao mercado". ${ }^{56} \mathrm{~A}$ maioria dos homens e mulheres concordou que o salário era razoável, mas que podia melhorar para refletir a realidade. O pagamento inicial para um policial é N42,000 ou o equivalente a US\$280, o que aumenta à medida que ele ou ela é promovido. ${ }^{57} \mathrm{~A}$ maior parte do trabalho é feito por este nível de homens e mulheres em um contexto de equipamentos inadequados. Muitas vezes, eles tiveram que usar seus próprios recursos para apoiar seu trabalho. ${ }^{58}$

Sobre a disponibilidade de outros subsídios e benefícios, especialmente levando-se em consideração a natureza propensa à crise da área, todos os meus correspondentes disseram em coro que "não havia nenhum outro subsídio exceto nossos salários". ${ }^{59}$ Um oficial da polícia cinicamente observou que a maneira com que o funcionário da polícia realiza o seu trabalho era realmente de sua própria responsabilidade criativa, enquanto eles apresentassem resultado, "improvisamos a maior parte do tempo

55 Entrevista, Comando de Polícia de Plateau, 23/03/13

56 Entrevista, Comando de Polícia de Plateau, 18/03/13.

57 Trabalho de campo, 28/03/13.

58 Enquanto estava no meu trabalho de campo e realizando entrevistas, o policial recebeu um telefonema em seu celular pessoal sobre um acidente. Ele mandou um homem de patrulha para o local e disse-me que, porque o único veículo de patrulha na divisão está longe, o homem de patrulha vai ou usar seu dinheiro, ou caminhar até o lugar. Poucos minutos depois, ele foi informado de que as pessoas envolvidas estavam caminhando para a estação. Trabalho de campo, 28/03/13.

59 Entrevista em grupo, Comando de Polícia de Plateau, 19/03/13. 
quando não temos as ferramentas para o trabalho". $60 \mathrm{Na}$ opinião de meus correspondentes:

As lideranças estão cientes do problema dentro da força. A atitude geral é de não fazer nada pois a podridão é profunda e há poucos funcionários e homens comprometidos e, por causa da tendência geral de corrupção de cima a baixo, aqueles comprometidos tinham a opção de seguir duas tendências: ou fazendo mudanças silenciosas onde eles podem, ou mantendo o silêncio e calando a boca. ${ }^{61}$

A era de quartéis para os policiais está se tornando uma coisa do passado. A maioria dos quartéis existentes nas divisões ou foram herdados da autoridade colonial ou foram construídos nos primeiros anos da independência ou sob a administração da Segunda República. Ironicamente, são aqueles herdados da autoridade colonial que ainda resistem ao teste do tempo. Aqueles construídos pelo governo pós colonial foram renovados várias vezes e ainda parece que eles vão cair a qualquer momento. ${ }^{62} \mathrm{~A}$ minha interação com os oficiais e os homens mostrou que a maioria dos policiais mora fora do quartel, uma vez que eles são totalmente inadequados para acomodá-los. Bairros específicos, especialmente perto das formações policiais, tornaram-se espécies de quartéis. Este é o caso das ruas como Jenta Makeri, Jenta Adamu, Jenta Mangoro e Tudun Wada. ${ }^{63}$ Os quartéis das Divisões - e existem poucos desse tipo - não são estritamente para uso divisional, pois é possível encontrar oficiais e homens de outras divisões vivendo neles. Sob impacto dessa situação, para mobilizar os homens em tempos de crise, minha interação demonstrou que existem desafios que têm de ser superados de alguma forma. Um oficial elogiou a vinda da comunicação móvel para preencher esta lacuna ${ }^{64}$ e outro era da opinião de que viver dentro da comunidade, e não no quartel, serve para fornecer inteligência preventiva útil. ${ }^{65}$

A maioria dos meus entrevistados acredita que as reformas na polícia -e inúmeras delas são necessárias - não vão funcionar por causa da corrupção no sistema. Eles acreditam que a perspectiva de construção de novos escritórios ou quartéis está fora de questão, muito menos irá melhorar a situação dos atuais. Um entrevistado questionou o fato de que as reformas

60 Entrevista, Delegacia de Polícia, Jos, 14/03/13; improvisação aqui refere-se a atividades ardilosas comuns à polícia na Nigéria.

61 Entrevista, Delegacia de Polícia, Jos, 14/03/13. Muitas vezes citados como exemplos de quem falou e foi punido são o Superintendente Alozie, Ogugbuaja, oficiais subalternos marcantes e, recentemente, CP Emmanuel Ayeni.

62 Observação pessoal na área metropolitana de Jos. Na verdade, uma estrutura de dois andares colocada no local há menos de 30 anos atrás, quando comparada com a estrutura colonial muito antiga e resistente, representa uma metáfora da decadência da força policial. As famílias que vivem no interior do edifício são evidências da falta de preocupação da autoridade e do risco que as pessoas podem correr.

63 Trabalho de campo, Comando de Polícia de Plateau.

64 Entrevista, Comando de Polícia de Plateau, 23/03/13

65 Entrevista, Comando de Polícia de Plateau, 22/03/13 
só funcionam quando a liderança da força quer que elas funcionem. As reformas, de acordo com o meu entrevistado, deveriam ser

sobre a instituição e não pessoais (...) veja o que aconteceu com um comissário de polícia aposentando no comando da polícia do Estado de Plateau, por ousar dizer como ela é! Que se pode ser repreendido, mesmo estando naquele nível, e quando você é aposentado, isso revela o alcance da autoridade decorrente de dissidência positiva. Lembre-se da greve iniciada por policiais há alguns anos atrás e o preço que eles pagaram?66

\section{Conclusão}

O ambiente de trabalho da polícia em Jos espelha a realidade das formações de polícia em todo o país. Há uma carência no que diz respeito à maioria das ferramentas de trabalho, incluindo equipamentos de comunicação, veículos de patrulha, subvenção, espaço de escritórios, mobiliário, equipamentos de escritório, instalações de lazer e conveniências, assim como banheiros. Não há dúvidas de que o desafio de governança que a Nigéria enfrenta está afetando a polícia. Como foi visto, há também a questão interna de má gestão e corrupção que está ampliando os desafios da governança. A corrupção é uma indústria em crescimento importante na Nigéria e, de acordo com o Bispo Hassan Kukah, é a única coisa que funciona no país. A polícia tem sido apontada como uma das agências mais corruptas, enquanto a corrupção permeia a maioria dos aspectos do trabalho policial.

Em primeiro lugar, sobre o fundo de apoio à liderança destinado a fornecer auxílio de trabalho para os homens e as mulheres da força, tais como uniformes, móveis, equipamentos de escritório, mesas, cadeiras, computadores e armários, bem como fundos para executar as divisões. Um Comandante Divisional Policial me informou que o subsídio oscila o tempo todo e os policiais já tiveram que usar seus próprios recursos para fornecer o próprio material de trabalho. Em segundo lugar, os funcionários se envolvem em diferentes práticas corruptas, incluindo suborno e extorsão de todos os tipos, em nome do fornecimento de material de trabalho. As inúmeras reformas na polícia, desde 1999, são alheias às ferramentas básicas de policiamento moderno, tais como laboratórios, base de dados de impressões digitais e auxílio forense. A infraestrutura para suportar equipamentos de policiamento moderno é inexistente, como resultado da corrupção endêmica, mas o país tem recursos humanos e materiais para proporcionar tal auxílio.

66 Entrevista, Comando de Polícia de Plateau, 22/03/13. 
As formações policiais na metrópole de Jos estão paralisadas por falta de equipamentos, remuneração adequada e alojamento para operar a nível ideal. Isto acontece a despeito do fato do Estado de Plateau estar em estado de emergência há mais de vinte anos. Os governos federal e estadual supostamente gastam grande quantidade de dinheiro para combater a irrupção contínua de conflitos usando equipamentos de emergência, tais como a Força Tarefa Unida e a Força Tarefa Estadual. Estes equipamentos são abastecidos regularmente com veículos de patrulha e equipamentos de comunicações. A polícia, treinada para executar essas tarefas quando os equipamentos de emergência eventualmente saem em campo, não tem acesso à essa logística.

A maioria dos funcionários das divisões onde eu realizei trabalho de campo são da opinião de que o fornecimento de equipamentos de escritório, veículos de patrulha, escritórios, melhor remuneração, subsídios e alojamento propício irá melhorar a sua eficiência. Por enquanto, esses são completamente ausentes em alguma instância ou são grosseiramente inadequados em outras, o que dificulta o desempenho das suas funções. 